\title{
Neumopatías agudas en el niño menor. Relación con la enfermedad bronquial obstructiva crónica
}

\author{
Drs, Patricia Iturra H.; Marina Guzmán M.;' Guido Girardi B.; ${ }^{2}$ Ramiro González V. ${ }^{3}$
}

\begin{abstract}
Acute Pneumonia in young children. Helationships with Chronic Obstrucbive Bronchial Disease

In 172 children admited with diugnosis of Pneumonia or Bronchopneumonia, we found that $64 \%$ of them had Chronic Obstrnctive Bronchial Disease (COBD).

It is enphasized the need of early use of branchodilators in these children to avoid latter morbidity and frecuent admissions.
\end{abstract}

La enfermedad Bronquial (Obstructiva Crónica (EBOC) tiene una alta prevalencia en los primeros años de la vida. Esta se explicaría por causas genéticas y ambientales, por la inmadure $z$ inmunológica y las muy particulares características anátomo-funcionales de la vía aérea a esta edad. Todos estos factores conducen a la expresión de una hiperreactividad bronquial e inciden directamente en la mayor gravedad que la enfennedad alcanza en este período de la vida. Por los antecedentes expresados nos pareció lógico suponer que la EBOC tenía que jugar un rol importante como factor de riesgo de hospitalización por nemopatía aguda (NA), lo que nos indujo a iniciar este estudio.

\section{MATERIAL Y METODO}

Seleccionamos al azar 172 niños cuyas edades tluctúan entre los seis meses y los cinco años seis meses, en un $85 \%$ de los casos eran lactantes que se internaron en nuestro hospital por NA, durante el año 1980. En forma paralela a los datos obtenidos por el medico tratante, elaboramos una exhaustiva anamnesis, que nos permitiera descubrir la existencia de EBOC previa. Con posterioridad al alta, analizanos el examen físico descrito en la ficha de hospitalización, las características del hemograma y de la radiografía de tórax, así como el tratamiento y evolución.

Con estos elementos hicimos un diagnóstico

\footnotetext{
Médicos becarins. Servicio de Pediatria. Hospital Exerguel González Contés. Depto. de Pediatríd y Cirugcia lutantil Sur. Ficcultad de Medicina. Lniversidaul de Chile.

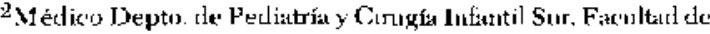
Medicinat Universirlad de Chule.

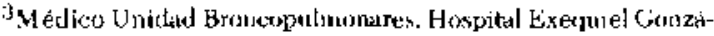
lez Ciortés.
}

definitivo sobre el tipo de neumopatía que había causado la intemación, comparándolo con el que se hizo al ingreso y al alta. Luego del egreso los pacientes fueron controlados durante un año, a fin de vigilar la aparición de nuevas afecciones respiratorias y los rasgos clínicos de éstas.

\section{RESULTADOS}

El promedio de edad del grupo estudiado fue de un año cuatro meses (Tabla 1). El 57\% de los sujetos era de sexo masculino.

Tabla ג

Distribución según edad del grupo estudiado.

EDAD

$\begin{array}{lr}\text { Lactantes }(6-24 \mathrm{~m}) & 147(85,4 \%) \\ \text { Preescolares } & 25(14.6 \%) \\ \text { Edad promedio } & 1 \text { a } 4 \mathrm{~m} .\end{array}$

Al ingreso al hospital se hicieron con frecuencia varios diagnósticos simultáneos y se diagnósticó Neumonia (N) o Bronconeumonía (BRN) en 145 niños $(85,4 \%)$. Este diagnóstico se mantuvo al alta en 128 casos $(64,4 \%)$ y en forma definitiva, luego de nuestro análisis, sólo en 88 (51\%). De estos casos 57 ( $60 \%)$, presentaron una neumopatía de origen probablemente bacteriano y en los restantes los hechos clínicos y de laboratorio sugerían que la etiología viral era lo mas probable. Después de $\mathbf{N}$ o BRN el diagnóstico planteado con inás frecuencia, fue el de Bronquitis Obstructiva Aguda (BOA), que fue hecho al ingreso en 82 individuos, mantenido al alta en $53(30,8 \%)$, pero el estudio posterior indicó que sólo 38 (22\%) correspondian realunente a él. (Gráfico 1). 


\section{Gráfico l}

Comparación de los diagnósticos de ingreso, egreso y definitivo.

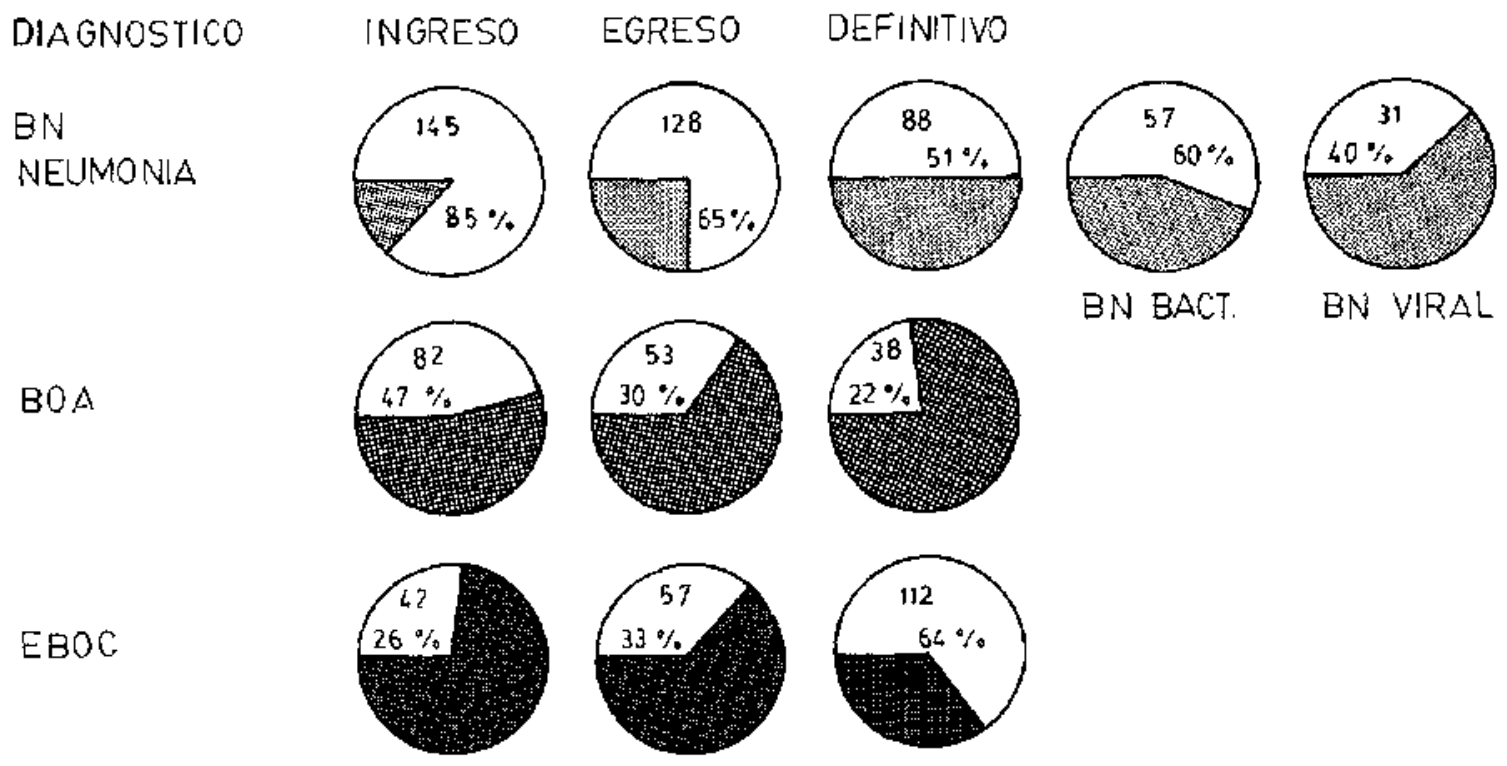

EBOC se planteó al ingreso sólo en $\mathbf{4 2}$ nin̄os (26\%), cifra que subió a $57(33 \%)$ al alta. Definitivamente resultaron tener una EBOC 112 pacientes (64\%). (Gráfico 1).

En el examen físico, 143 sujetos tuvieron signos bronquiales de abstrucción, 52 signos sospechosos de BRN y 60 Síndrome de Condensación.
En la radiogralía de tórax habia "hiperinsuflación" en 135 casos (78,5\%), "peribronquitis" en $57(30 \%)$, "condensación" en $66(38 \%)$, atelectasia en $25(14,5 \%)$, "neumonitis" en $17(10 \%)$ y "derrame pleural" sólo en 9 oportunidades $(5 \%)$. (Gráfico 2).

El análisis del tratamiento demostró que reci-

\section{Gráfico 2}

Resultados de la Rx de Tórax.

HIPERINSUFLACION

PERIBRONQUITIS

CONDENSACION

ATELECIAS!A

NEUMONITIS

DERTAME

CARDIOMEG I I CVP

DESV. MEDIAST

EDEMA PULM.

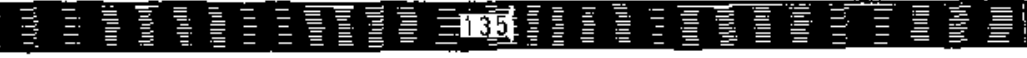

$30 \%$

$38 \%$
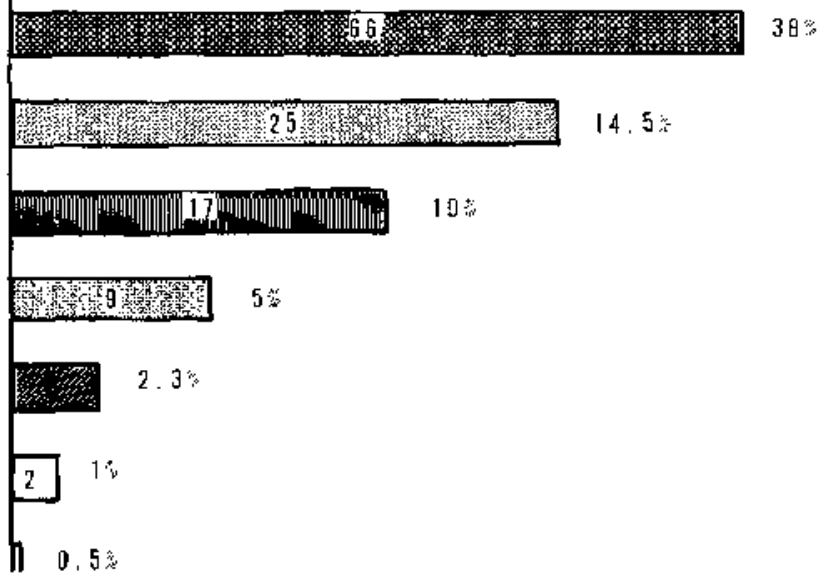

2. $3 \%$ 


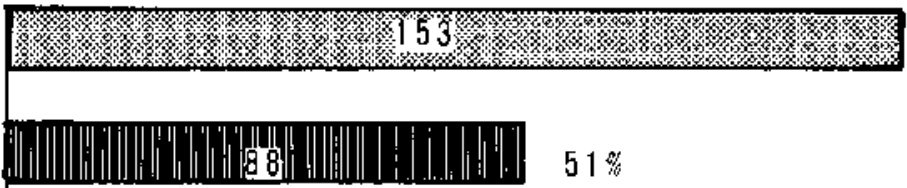

BRDNCODILATADOR

CORTICOIDES

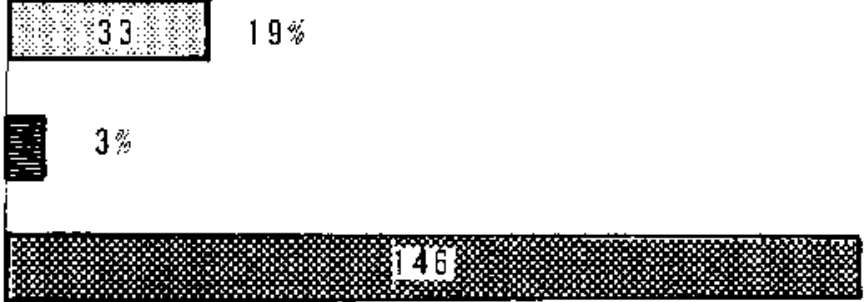

ANTIB. CORTICOIDE

KINES I TERAPIA

bieron antibióticos 153 niños (89\%), broncudilatadores $88(51 \%)$, corticoides 33 (19\%), antibióticos más corticoides $5(3 \%)$ y Kinesinterapia $84,5 \%$ de los pacientes (Gráfico 3 ).

Estudiando la correlactón entre los diagnósticos de ingreso y egresa y el definitivo, pudimos establecer que esta fue buena en $48(28 \%)$, regular en $81(47 \%)$ y mala en $43(25 \%)$ de las oportunidades. (Tabla 2).

Tabla 2

Correlación entre los diagnósticos de egresos y defiuitivo.

\begin{tabular}{lll} 
Buena & 48 & $(28 \%)$ \\
Regular & 81 & $(47 \%)$ \\
Mala & 43 & $(25 \%)$ \\
\hline
\end{tabular}

\section{COMENTAFIO}

Para comprender mejor los resultados de este estudio, es necesario tener presente que la gran mayoria de los sujetos investigados fueron lactantes. Los datos presentados resaltan que la EBOC condiciona la mayoría de las hospitilizaciones por $\mathrm{NA}(64 \%)$ en los primeros años de vida. Esto nos explica el predomirio masculino, la alta frecuencia con la que se pesquisó signologia broncjuial obstructiva al examen fisico y su consecuencia radiológica (la hiperinsullación), así como el frecuente uso de broncodilatadores, corticoides y Kinesioterapia respiratoria.

Los resultados obtenidos también demuestran que las descompensaciones agudas de la EBOC inducen numerosas veces a plantear erróneamente la existencia de BRN o $\mathrm{N}$ y por ende al uso injustificado de antibióticos. Del mismo modo se podría explicar que este diagnóstico sea mantenido a pesar de no contar con elementos clinicos, ni de laboratorio que lo fundamenten. Esta investigación sugiere el importante rol que juegan los virus, en la producción de patología respiratoria baja, en los primeros años de vida. ${ }^{1-4}$ Ellos serian los responsables de casi todas las BOA y de la gran mayoría de las descompensaciones agudas de la EBOC, a los que debemos agregar que el $40 \%$ de los niǹos que tưieron $\mathrm{N}$ o BRN tenían signos que sugerian la posibilidad de una etiologia viral.

Los hallazgos descritos debieran servir al pediatra que enfrenta una NA con signos bronquiales obstructivos, para que considere la $\mathrm{EBOC}$ entre los diagnósticos y el uso de broncodilatadores en el tratamiento, ya que si bien ha habido discusión acerca de su utilidad en el menor de 18 meses, cada vez aparecen mayores evidencias que apoyan su empleo. ${ }^{5,3}$

Los hallazgos de este trabajo tienen importantes implicaciones epidemiológicas $\mathrm{y}$ asistenciales, en cuanto a la asignación de recursos, por cuanto se ha demostrado que el buen manejo ambulatorio de la $E B O C$, tendiente a evitar las descompensaciones, disminuye en fonna notoria sus complicaciones y la necesidad de hospitalizaciones.

\section{CONCLUSIONES}

Existe consenso acerca de la importancia de la EBOC en la patología respiratoria crónica del ni- 
ño. Debemos agregar ahora que sus descompesaciones agudas son condicionantes de un gran número de hospitalizaciones y con alta frecuencia inducen a diagnosticar erróneamente $\mathrm{NA}_{2} y$ a usar mal los antibióticos.

Muchos trabajos evidencian el rol preponderante que juegan los virus como agentes etiológicos y factores desencadenantes de patología de las vias respiratorias bajas, en el grupo etario estudiado.

Es altamente aconsejable limitar el uso de antibióticos a situaciones en que existan elementos clínicos $y$ de laboratorio que hagan sospechar fuertemente la etiología bacteriana.

También sería recomendable tratar de identificar mediante la anamnesis la presencia de EBOC en todo paciente con neumopatía aguda asociada a signos bronquiales obstructivos, con el fin de utilizar broncodilatadores.

Reiteramos que un adecuado manejo ambulatorio de la $\mathrm{EBOC}$ reduce en forma considerable el número de hospitalizaciones en estos pacientes.

\section{HESUMEN}

Se estudian 172 niños hospitalizados por Neumopatia Aguda, en su mayoria lactantes. Se demuestra que en el $64 \%$ de ellos existía de base
EBOC y gue frecuentemente, la gravedad de las descompensaciones de esta enfermedad, indujo a plantear erróneamente el diagnóstico de Bronconeumonja o Neumonia. Entre los pacientes en los que estos diagnósticos se confimaron, un $40 \%$ tuvieron cuadros cuya etiología más probable fue viral, por lo cual se recalca la importancia de estos agentes en la producción de patología respiratoria baja en el grupo etario estudiado. En la mitad de los casos se usaron los broncodilatadores como principal arma terapéutica. Se hace hincapié en la necesidad de tal terapia en vista de la evidencia sobre su efectividad en el menor de 18 meses.

\section{REFERENCIAS}

${ }^{1}$ Minor TH et al. Viruses as precipitans of astmmatic attacks in children. JAMA 22 $\mathbf{7} ; 292,1974$.

${ }^{2} \mathrm{Mc}$ Intosh $e t a l$. The assoutiation of viral and bacterial respirato$r y$ infections with exacerhations of wheezing in young asthnuatic childrens Pedianics 82: 578, 1973.

${ }^{3}$ Freeman G., Todd $\mathbf{R}$. The role of allergy in viral respirutory tract infections Am. J. Dis. Child. 104; 330, 1973.

${ }^{4}$ Welliver R.C. et al. The appearence of allbound $\mathrm{IgE}$ in respiratory tract epithelium after Hespiratory Sincytial virus infections. New Engls. J. Med 274: 715, 1980 .

5 Tabachnick E. et al. Infantil Bronchial Asthma J. Allert. Clin [ı11)

${ }^{6}$ Holland $\mathrm{C}$. et at. Measurement al respiratory etfiort and assesment of a method of treatment for lower respinatory tract infectbons in small childrens. Lancer $2 ; 1166,1960$. 